University of Wisconsin Milwaukee

UWM Digital Commons

Geography Faculty Articles

Geography

$11-2014$

\title{
Regionalization of Hydrologic Response in the Great Lakes Basin: Considerations of Temporal Scales of Analysis
}

Jonathan Martin Kult

University of Wisconsin-Milwaukee, jmkult@uwm.edu

Lauren M. Fry

University of Michigan-Ann Arbor

Andrew D. Gronewold

National Oceanic and Atmospheric Administration

Woonsup Choi

University of Wisconsin - Milwaukee, choiw@uwm.edu

Follow this and additional works at: https://dc.uwm.edu/geog_facart

Part of the Geography Commons

\section{Recommended Citation}

Kult, Jonathan Martin; Fry, Lauren M.; Gronewold, Andrew D.; and Choi, Woonsup, "Regionalization of Hydrologic Response in the Great Lakes Basin: Considerations of Temporal Scales of Analysis" (2014). Geography Faculty Articles. 12.

https://dc.uwm.edu/geog_facart/12

This Article is brought to you for free and open access by UWM Digital Commons. It has been accepted for inclusion in Geography Faculty Articles by an authorized administrator of UWM Digital Commons. For more information, please contact open-access@uwm.edu. 
Regionalization of hydrologic response in the Great Lakes basin: Considerations of temporal scales of analysis

Jonathan M. Kult ${ }^{a, b}$, Lauren M. Fry ${ }^{b, c,}{ }^{*}$, Andrew D. Gronewold ${ }^{c}$, Woonsup Choi ${ }^{a}$

${ }^{\text {a }}$ Department of Geography, University of Wisconsin-Milwaukee, P.O. Box 413, Milwaukee, WI 53201-0413, USA

${ }^{b}$ Cooperative Institute for Limnology and Ecosystems Research, University of Michigan, Ann Arbor, MI 48108-9719, USA

${ }^{\mathrm{c}}$ Great Lakes Environmental Research Laboratory, National Oceanic and Atmospheric Administration, 4840 S. State Rd., Ann Arbor, MI 48108-9719, USA

* Corresponding author at: Cooperative Institute for Limnology and Ecosystems Research, University of Michigan, 4840 S. State Rd., Ann Arbor, MI 48108. Tel.: +1 734741 2217. E-mail address:Imfry@umich

This is an Accepted Manuscript of an article published by Elsevier in Journal of Hydrology in volume 519 in 2014, available online:

https://doi.org/10.1016/j.jhydrol.2014.09.083 
Abstract:

Methods for predicting streamflow in areas with limited or nonexistent measures of hydrologic response commonly rely on regionalization techniques, where knowledge pertaining to gauged watersheds is transferred to ungauged watersheds. Hydrologic response indices have frequently been employed in contemporary regionalization research related to predictions in ungauged basins. In this study, we developed regionalization models using multiple linear regression and regression tree analysis to derive relationships between hydrologic response and watershed physical characteristics for 163 watersheds in the Great Lakes basin. These models provide an empirical means for simulating runoff in ungauged basins at a monthly time step without implementation of a rainfall-runoff model. For the dependent variable in these regression models, we used monthly runoff ratio as the indicator of hydrologic response and defined it at two temporal scales: (1) treating all monthly runoff ratios as individual observations and (2) using the mean of these monthly runoff ratios for each watershed as a representative observation. Application of the models to 62 validation watersheds throughout the Great Lakes basin indicated that model simulations were far more sensitive to the temporal characterization of hydrologic response than to the type of regression technique employed, and that models conditioned on individual monthly runoff ratios (rather than long term mean values) performed better. This finding is important in light of the increased usage of hydrologic response indices in recent regionalization studies. Models using individual observations for the dependent variable generally simulated monthly runoff with reasonable skill in the validation watersheds (median Nash-Sutcliffe efficiency $=0.53$, median R2 $=0.66$, median absolute value of deviation of runoff volume $=13 \%)$. These results suggest the viability of empirical 
approaches to simulate runoff in ungauged basins. This finding is significant given the many regions of the world with sparse gaging networks and limited resources for gathering the field data required to calibrate rainfall-runoff models.

Keywords: runoff; regionalization; prediction in ungauged basins; hydrologic response; regression model; Great Lakes basin

1. Introduction

\section{1 Predictions in ungauged basins}

Addressing water quantity and quality issues is possible in gauged basins using rainfall-runoff models calibrated to streamflow observations. The need to address these issues over spatial domains with limited or nonexistent stream gage observation networks motivated the International Association of Hydrological Sciences Prediction in Ungauged Basins (PUB) Initiative (Sivapalan et al., 2003, Hrachowitz et al., 2013). While PUB research is typically conducted at local or regional scales, the challenges of understanding hydrological processes in data sparse locations are global. In fact, the least developed gaging networks are generally found in those regions most susceptible to hydrologic impacts from expanding populations and changes in land use and climate (Sivapalan et al., 2003). 
Traditional approaches to the PUB problem involve determining an appropriate parameter set for a rainfall-runoff model structure for application in the ungauged basin. Without the aid of streamflow observations for estimating these parameters, PUB research commonly employs regionalization techniques to establish relationships between gauged and ungauged watersheds (Vogel, 2006; Wagener et al., 2004). A variety of regionalization approaches have been developed for estimating parameter sets at ungauged sites. For example, a parameter set may be inferred for an ungauged watershed based on its spatial proximity or physical similarity to gauged watersheds (Mclntyre et al., 2005; Nijssen, 2001; Parajka et al., 2005; Reichl et al., 2009). Alternatively, parameter sets may be estimated at the ungauged site based on statistical relationships between calibrated parameters and watershed physical characteristics (Abdulla and Lettenmaier, 1997; Post, 2009; Post and Jakeman, 1999; Sefton and Howarth, 1998; Seibert, 1999). Frequently, these regionalization approaches are explored in tandem (Kokkonen et al., 2003; Merz and Blöschl, 2004; Samuel et al., 2011).

Regionalization techniques tied to rainfall-runoff model structures have been met with a variety of practical and theoretical challenges. For example, the suitability of a regionalization approach is both location specific (Bao et al., 2012; Beven, 2000; Oudin et al., 2008; Wagener and Wheater, 2006) and rainfall-runoff model specific (Bárdossy, 2007; Bevin, 2006; Kay et al., 2006). In response to the uncertainties introduced in model-dependent regionalization approaches, recent studies developed regionalization schemes that are model-independent (that is, they can be applied to any rainfall-runoff model). Wagener and Montanari (2011) review emerging methods wherein model-independent measures of hydrologic response in 
gauged watersheds (rather than direct streamflow observations) are employed to establish a regionalization scheme. A wealth of indices has been derived to implicitly quantify these processes (Olden and Poff, 2003). Examples include watershed input-output relationships (e.g. runoff ratio), hydrograph analytics (e.g. rising limb density) and metrics characterizing the magnitude, frequency, duration and timing of flow events (e.g. baseflow index and flood frequency).

Yadav et al. (2007) presented a rainfall-runoff model-independent approach to making predictions in ungauged basins based on empirical relationships between watershed physical characteristics and a variety of hydrologic response indices. Three response indices (runoff ratio, high pulse count and the slope of the flow duration curve) were shown to be useful for constraining ensemble predictions at ungauged sites. Shamir et al. (2005) developed two hydrograph-based response indices (rising and declining limb density) to improve the identification of optimal parameters for a process-based rainfall-runoff model; a case study employing this method indicated improved model reliability and predictive skill. Sawicz et al. (2011) developed a classification scheme for watersheds in the eastern U.S. that incorporated six hydrologic response indices observed to vary along a climate gradient: runoff ratio, baseflow index, snow day ratio, slope of the flow duration curve, streamflow elasticity, and the rising limb density.

Relationships between hydrologic response indices and watershed physical characteristics are typically used to provide ancillary information for rainfall-runoff modeling. For example, 
Bulygina et al. (2009) used this information to constrain the range of allowable values for model parameters. Alternatively, this information can be used to develop an ensemble of predictions based on the likelihoods of candidate models (Mclntyre et al., 2005; Reichl et al., 2009). Finally, some hydrologic response indices (e.g. runoff ratio) can be applied directly to simulate runoff in ungauged watersheds, as is demonstrated in this study. This approach is rainfall-runoff modelindependent in the sense that a process-based model is not implemented.

Hydrologic response indices have traditionally been developed to describe a watershed's typical behavior over a given period of time. For example, runoff ratio, also referred to as runoff yield, is a dimensionless index obtained by dividing total basin runoff by total basin precipitation over an equivalent time period. Yadav et al. (2007) defined runoff ratio as average annual runoff divided by average annual precipitation. Berger and Entekhabi (2001) and Sawicz et al. (2011) defined it more generally as the ratio of long-term runoff to long-term precipitation. Similarly, nearly all of the 171 response indices reviewed by Olden and Poff (2003) are derived as longterm mean values, representing the average watershed behavior over a given time period. Moreover, despite the fact that hydrologic response can exhibit substantial seasonal variability (see Section 4), runoff ratio has typically been defined at an annual time step. As a result, contemporary research utilizing hydrologic response indices has addressed the spatial, but not temporal, variability in watershed behavior.

This research gap is addressed by developing and regionalizing two different temporal characterizations of runoff ratio at a monthly time step, addressing the research question of 
how both interannual and seasonal temporal variability in hydrologic response affects predictions in ungauged basins. Specifically, the objectives of this study are to:

- Develop regression-based regionalization models between watershed physical characteristics and monthly runoff ratio as an index of hydrologic response;

- Use the models to simulate streamflow in ungauged basins at a monthly time scale without implementation of a rainfall-runoff model;

- Illustrate the effects of defining hydrologic response at different temporal scales (long-term average versus short-term indices) in terms of model skill and applicability to water resource management objectives;

- Assess the potential for regression tree models for hydrologic modeling alongside a commonly used multiple linear regression model.

1.2 Hydrologic modeling in the Great Lakes basin

We address our research objectives in the Great Lakes basin. The Great Lakes basin (Figure 1) drains over half a million square kilometers of land in the United States and Canada featuring varied land cover, climate, subsurface characteristics and human activity. Figure 1 shows dominant land cover type throughout the basin by U.S. Geological Survey (USGS) 12-digit hydrologic unit code (HUC12) delineations (USGS, 2012). The basin is home to over 30 million residents, many of whom live in highly urbanized areas adjacent to the lakes. Temperature and precipitation variability is a function of both latitudinal and lake effects (Choi et al., 2012; 
Norton and Bolsenga, 1993). Significantly different subsurface properties exist throughout the basin as a result of the geologic formation of the Great Lakes. At the scale of the Great Lakes basin, this variability results in a wide range of potential hydrologic response among watersheds, both gauged and ungauged.

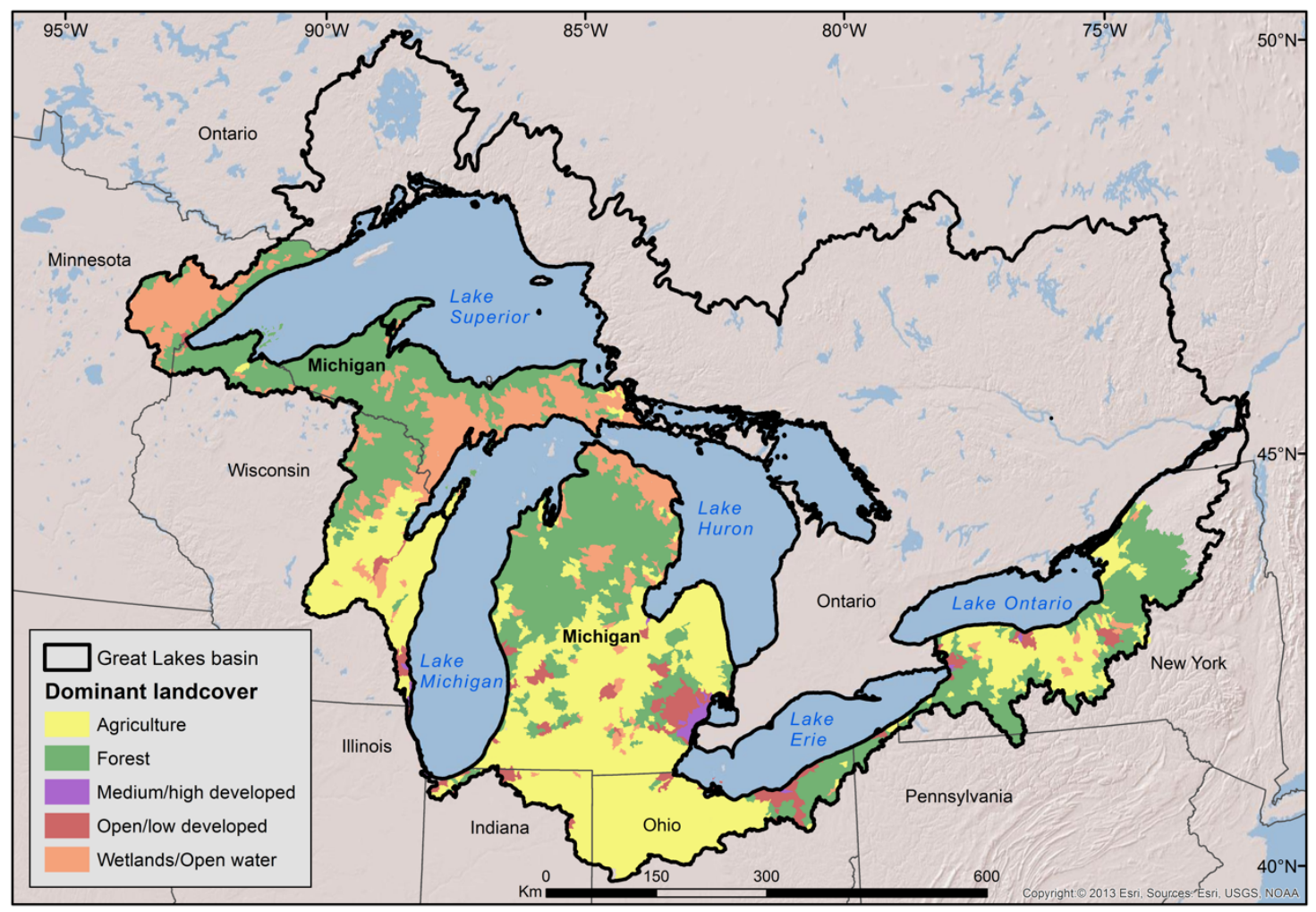

Figure 1.

Predictions in ungauged portions of the Great Lakes basin are essential for research and management objectives related to the effects of land use/land cover change on near-shore ecosystems (Wolter et al., 2006); nonpoint source pollution loadings (He and DeMarchi, 2010); net water supply availability for irrigation, hydropower, and human consumption (Changnon, 
1987; He, 1997), and lake level forecasting to support the needs of transportation and recreation industries (Gronewold et al., 2011; Lee et al., 1997). In recent years, the need to reduce uncertainty in each of the components of the Great Lakes basin water budget has become increasingly clear due to dramatic changes in water level dynamics (Gronewold and Stow, 2014) . Complete spatial coverage of runoff estimates throughout the Great Lakes basin is critical for preparing reliable water level forecasts and for understanding the mechanisms involved in fluctuating water levels. A number of recent workshops and regional studies have resulted in recommendations to improve basin-wide runoff estimates (Coon et al., 2011; Fry et al., 2013; Gronewold and Fortin, 2012; Gronewold et al., 2011).

As a study area, the Great Lakes basin poses unique challenges for making predictions in ungauged watersheds. For example, there is a clear siting bias in the U.S. stream gage network, with coastal areas primarily ungauged and inland areas predominantly gauged (see Figure 2). Moreover, due to its large size and transnational data coordination efforts, many models have been applied within the Great Lakes basin to individual tributaries or portions of the basin within national boundaries, but few estimates of runoff to the entire system exist (Coon et al., 2011). 

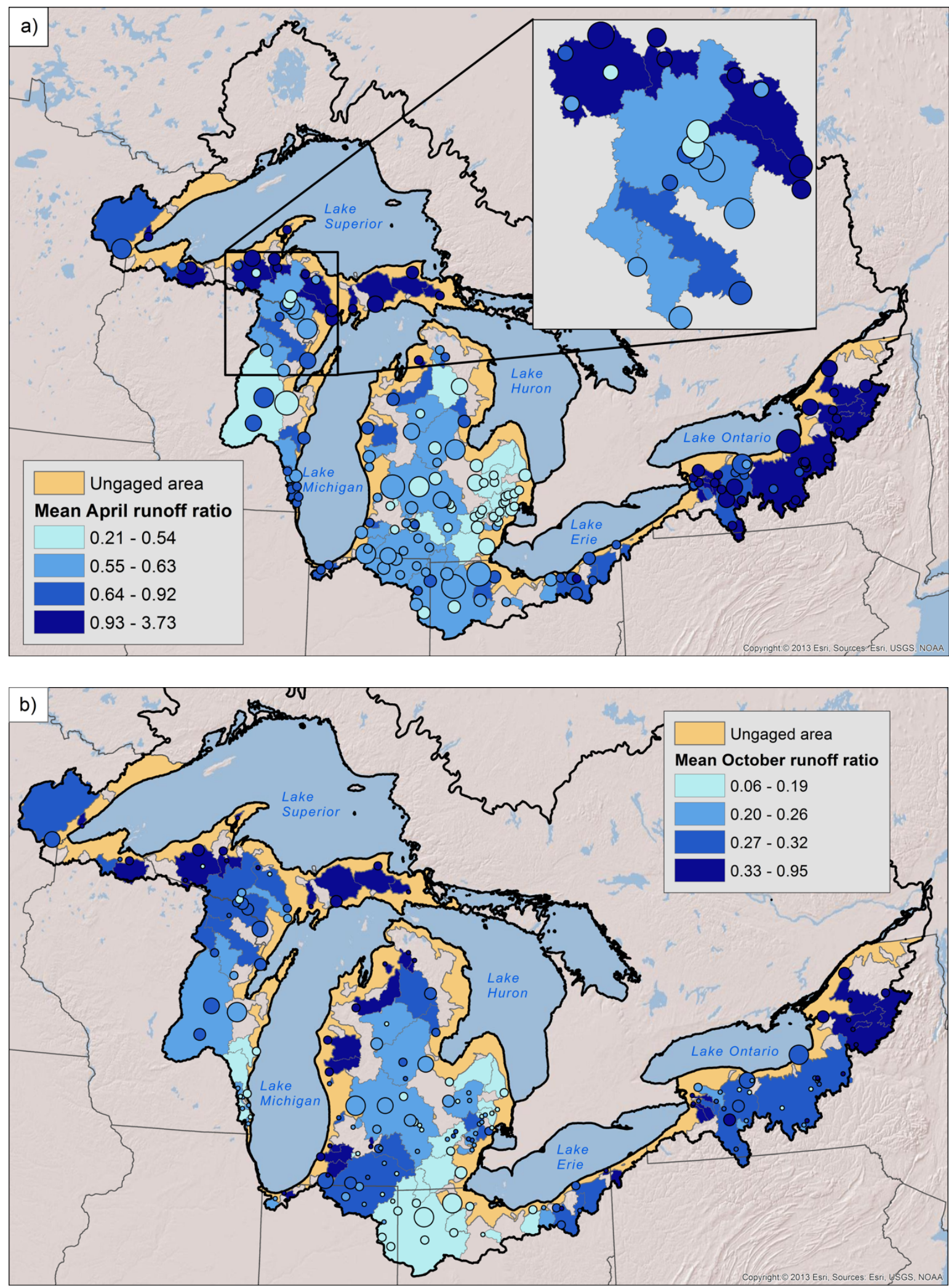

Figure 2. 
Basinwide products include the conceptual Large Basin Runoff Model (LBRM) developed by the National Oceanic and Atmospheric Administration's Great Lakes Environmental Research Laboratory (NOAA-GLERL; Croley and Hartmann, 1986) and the physically-based Modeling Environment Community Surface Hydrological (MESH) model developed by Environment Canada (Pietroniro et al., 2007). LBRM and MESH are rainfall-runoff models and therefore subject to the complications and limitations discussed above.

An alternate regionalization approach involving a simple area ratio method (ARM) has been an important component of Great Lakes regional hydrologic research for several decades (Croley and Hartmann, 1986; Fry et al., 2013). As implemented by NOAA-GLERL, the ARM identifies the most downstream gage(s) for each of 121 subbasins spanning the Great Lakes basin and extrapolates streamflow from gauged to ungauged regions based on the ratio of gauged to total subbasin drainage area. Advantages of the ARM include the high temporal resolution of the data (daily streamflow observations) as well as computational and conceptual simplicity. The primary disadvantage of the area ratio approach lies in its assumption of spatial homogeneity among the watershed physical characteristics influencing hydrologic response. Both the ARM and the models developed in this study involve regionalization of hydrologic response (streamflow and runoff ratio, respectively), resulting in empirical rather than conceptual or physically based rainfall-runoff models.

\section{Data and methods}




\subsection{Watershed physical characteristics}

The regionalization models developed in this study take into account the spatial heterogeneity of watershed physical characteristics not explicitly accounted for by the area ratio method. Watershed physical characteristics were obtained from the Geospatial Attributes of Gages for Evaluating Streamflow (GAGES-II) dataset (USGS, 2011). The geospatial data contained in GAGES-II include several hundred variables related to climate (long term average monthly or annual), soils, land cover, topography, geomorphology, and anthropogenic modifications for 450 gauged watersheds within the Great Lakes basin. Criteria for inclusion in the GAGES-II dataset were gages with at least 20 complete years of daily discharge record since 1950, or currently active gages as of water year (WY) 2009.

In GAGES-II, land cover variables are derived from the 2006 National Land Cover Dataset (NLCD) and soils variables from the State Soil Geographic (STATSGO) database. A wide range of variables describing watershed geomorphology, hydrology and topography are derived from national hydrography and Digital Elevation Model datasets.

Climate variables within the GAGES-II dataset are derived from PRISM Climate Group datasets. Percent snow is defined as the ratio of annual snow water equivalent to annual precipitation, thus serving as proxy to seasonal snowpack accumulation and ablation processes. The precipitation seasonality index ranges from zero to one, with higher values indicating higher seasonality of precipitation. 
Additional derivations and sources of variables in Table 1 are documented in detail by USGS (2011). The two exceptions are (1) a monthly wetness index computed as the ratio between monthly precipitation and potential evapotranspiration and (2) the Standardized PrecipitationEvapotranspiration Index (SPEI) developed by Vicente-Serrano (2010). Both the wetness index and SPEI were calculated in R using the SPEI package. The wetness index and SPEI both characterize water balance surplus-deficit conditions by month. SPEI additionally considers surplus-deficit conditions from prior months in its derivation. The variables percent snow, precipitation seasonality index, wetness index, and SPEI are included as attempts to address seasonal water balance dynamics obscured by binning precipitation and runoff by month.

Table 1 lists all watershed physical characteristics from GAGES-II considered for inclusion in the regionalization models. To develop the models, 12 variables (highlighted in grey in Table 1) were retained based on:

- Variable significance at the $p<0.05$ level over most of the year based on a preliminary assessment by fitting monthly linear regression models;

- An attempt to achieve minimal redundancy among variables (colinearity), informed by assessing Pearson correlation coefficients (results not shown);

- Representation of climate, soils, land cover, topography and geomorphology variables;

- Availability of data with complete spatial coverage over the U.S. portion of the Great Lakes basin. 
2.2 Monthly runoff ratio (MRR)

Daily USGS streamflow observations and NOAA precipitation data for each watershed were obtained from NOAA-GLERL. Daily areal precipitation for each watershed was estimated by kriging point observations from the precipitation gaging network in the GLERL

Hydrometeorological Database (see Hunter and Croley (1993) for details on the gage network used). Daily streamflow and precipitation data were aggregated by month for computing monthly runoff ratio.

Monthly runoff ratio (monthly runoff divided by monthly precipitation) was calculated for the 163 Great Lakes basin watersheds in the GAGES-II dataset with continuous flow records for water years (WY) 1981-2010. As the dependent variable in our regression models, we calculated monthly runoff ratio at two temporal scales: (1) treating all monthly runoff ratios as individual observations $\left(M R R_{i}\right)$ and (2) using the mean of these monthly runoff ratios for each watershed as a representative observation $\left(M R R_{m}\right)$. Table 2 summarizes the distinctions between the two temporal characterizations of runoff ratio, including potential management applications and perceived limitations of each. The last row in the table recalls the fact that long-term averages of hydrologic response have dominated contemporary PUB-related research. Runoff ratios were log transformed prior to developing the regression relationships in order to linearize the input for the regression models, as well as prevent the possibility of negative runoff simulations by the models. 


\subsection{Model development and validation}

Two regionalization models, multiple linear regression and regression tree, were developed and implemented in the R software package (R Development Core Team, 2011) to relate $M R R_{i}$ (or $M R R_{m}$ ) with watershed physical characteristics. The multiple linear regression model was of the form

$$
y=\beta_{0}+\beta_{1} x_{1}+\beta_{2} x_{2}+\ldots+\beta_{n} x_{n}+\varepsilon
$$

where the response variable, $y$, was monthly runoff ratio and the explanatory variables, $x$, were the $n=12$ watershed physical characteristics highlighted in Table 1 . Regression coefficients are denoted by the $B$ terms, while $\varepsilon$ is an error term, or residual, representing the difference between modeled and actual runoff ratio values.

Regression tree models have previously been used in regionalization studies. For example, regression trees have been used to extrapolate water quality data from monitored to unmonitored streams (Robertson and Saad, 2003), group catchments for predict low flow (Laaha and Blöschl, 2006), classify catchments according to flow regimes (Snelder et al, 2009), and identify drivers of hydrological response within a region (Ali et al., 2010). Regression tree routines in package rpart (Therneau and Atkinson, 2011) are based largely on the Classification and Regression Tree methodology of Breiman et al. (1984). Trees in rpart are 
grown so as to maximize differences in watershed characteristics at each branching in a simple analysis of variance. The resulting trees are then pruned to minimize the risk of misclassifying an observation while avoiding excessive model complexity or overfitting.

For our models, pruning was based on a threshold of 0.01 for the reduction in error from a leave-one-out cross-validation. For our experimental design, we considered it important for a single threshold to be used consistently for all models. The threshold of 0.01 was based on trial and error and multiple thresholds were tested and considered. Thresholds less than 0.01 generally led to insignificant model improvements at the cost of increased model complexity. Based on tests using thresholds greater than 0.01 , we judged that the improvement in model skill warranted the outcome of slightly more complex models.

The outputs from the regression tree analyses in rpart are monthly decision trees, with binary splits based on values of watershed physical characteristics, and terminal nodes grouping the 163 gauged watersheds into clusters (ideally) exhibiting similar hydrologic response. From the PUB perspective, rpart can then assign cluster membership to an ungauged watershed based on its physical characteristics. As a decision tree technique, there is no general equation to describe the regression tree process.

The four models (multiple linear regression and regression tree, conditioned by both $\mathrm{MRR}_{\mathrm{i}}$ and $M R R_{m}$ ) are then used to simulate monthly runoff at 62 validation gauges (Figure 4). Validation gauges included all USGS gauges for which continuous discharge observations were available 
for WY 2001 to 2010, but not WY 1981 to 2010, so there would be no overlap with the 163 gauges used for model development. Data for the validation watersheds were also obtained from the GAGES-II dataset. None of the validation watersheds were among the 163 watersheds used to develop the models.

The Nash-Sutcliffe coefficient of efficiency (NSE) (Nash and Sutcliffe, 1970), the coefficient of determination $\left(R^{2}\right)$, mean absolute error (MAE), and deviation of runoff volumes $\left(D_{v}\right)$ were computed to compare monthly simulated runoff $(P)$ versus monthly observed runoff $(O)$ in validation watersheds for all months $i$ during WY 2001-2010 $(n=120)$. NSE (Equation 2$)$ and $R^{2}$ (Equation 3) are goodness-of-fit statistics; MAE (Equation 4) quantifies error in units of $\mathrm{mm}$ of runoff; and $D_{v}$ (Equation 5) assesses model bias in terms of total cumulative runoff.

$$
\begin{aligned}
& N S E=1-\frac{\sum_{i=1}^{n}\left(O_{i}-P_{i}\right)^{2}}{\sum_{i=1}^{n}\left(O_{i}-\bar{O}\right)^{2}} \\
& R^{2}=\left[\frac{\sum_{i=1}^{n}\left(O_{i}-\bar{O}\right)\left(P_{i}-\bar{P}\right)}{\sqrt{\sum_{i=1}^{n}\left(O_{i}-\bar{O}\right)^{2}} \sqrt{\sum_{i=1}^{n}\left(P_{i}-\bar{P}\right)^{2}}}\right]^{2} \\
& M A E=\frac{1}{n} \sum_{i=1}^{n}\left|O_{i}-P_{i}\right| \\
& D_{v}=\frac{\sum_{i=1}^{n}\left(P_{i}-O_{i}\right)}{\sum_{i=1}^{n} O_{i}} \times 100
\end{aligned}
$$


For the NSE and $R^{2}$ statistics, values of one indicate a perfect model fit, where simulated runoff is equal to observed runoff. For $D_{v}$, a value of zero implies no model bias, where cumulative simulated and observed runoff (here, for WY 2001-2010) are equal. MAE quantifies the difference between observed and simulated values in actual units, in this case millimeters of runoff. Values closer to zero indicate a better model fit. The performance ratings for NSE and $D_{v}$ suggested by Moriasi et al. (2007), shown in Table 3, were used to evaluate model skill. Since $R^{2}$ is highly sensitive to outliers, Moriasi et al. (2007) do not provide performance ratings for this statistic, but consider a value greater than 0.50 to generally be acceptable.

We evaluate the effect of spatial aggregation by evaluating the goodness of fit statistics for the sum of discharge simulations at all 62 gages compared with the sum of discharge observations at those gages. Additionally, we investigate the influence of elapsed time on model skill by evaluating goodness of fit statistics over elapsed time, similar to methods described by Valipour et al. (2013).

\section{Results}

Figures 2 and 3 illustrate the spatial and temporal variability of monthly runoff ratio in the U.S. portion of the Great Lakes basin. Figure 2 depicts 30-year mean monthly runoff ratios (MRR $)$ for April and October for the 163 gauged watersheds used to develop the regionalization models. Watersheds are shown as point symbols graduated by drainage area, with the largest of any nested watersheds shown as polygons. Note the different ranges for $\mathrm{MRR}_{\mathrm{m}}$, symbolized 
by quartiles, between April and October, which are typically high and low flow periods, respectively.

Spatial trends include very high April runoff ratios in northern Michigan and western New York. Both regions frequently receive large amounts of snow throughout the winter due to lake effect processes, resulting in April runoff volumes that are much greater than April precipitation volumes due to melting of the snowpack. In contrast, very low October runoff ratios are observed throughout the predominantly agricultural regions of eastern Michigan and northern Ohio, where most incoming precipitation is subsumed by plants and soils.

Beyond these few instances, however, there is limited potential for generalizing hydrologic response solely by geographic regions. Throughout most of the Great Lakes basin, widely differing runoff ratios exist between spatially proximal watersheds, for example in northern Wisconsin and northern Michigan where $\mathrm{MRR}_{\mathrm{m}}$ ranged from 0.25 to 1.95 . This area is shown in the inset in Figure 2a. Climatic factors are largely constant at this spatial scale and the differences in dominant land cover shown in Figure 1 do not appear to correspond to the observed differences in runoff ratio. Additionally, there is no apparent relationship between these differences in hydrologic response and the soils characteristics used in our regression models. However, these characteristics are average values aggregated by watershed, and soil characteristics vary considerably over space in this area due to the glacial history of the region. In addition, there are 60 major dams (per the GAGES-II dataset) along the rivers in these watersheds, and these flow impediments may influence streamflow observations binned at a 
monthly time step. Our analysis did not identify the influence of dams on the success of the models; future work should investigate the sensitivity of both the models to the presence of dams by developing the models in unaffected watersheds separately.

Figure 3 presents the full range of seasonal and interannual variability in observed $M_{R R}$ (left panel) and $\mathrm{MRR}_{\mathrm{m}}$ (right panel). Substantial seasonal variability is evident in Figure 3, with higher magnitudes and larger ranges for runoff ratio during winter and early spring compared to summer months. In Figure 3, values greater than one indicate monthly watershed surpluses. Surpluses are common during winter and early spring months throughout the basin due to snowpack accumulation and ablation processes as well as minimal evapotranspiration and high soil water content at this time of year. On the other hand, surpluses are rare during summer and autumn months due to high levels of evapotranspiration and low soil water content. 


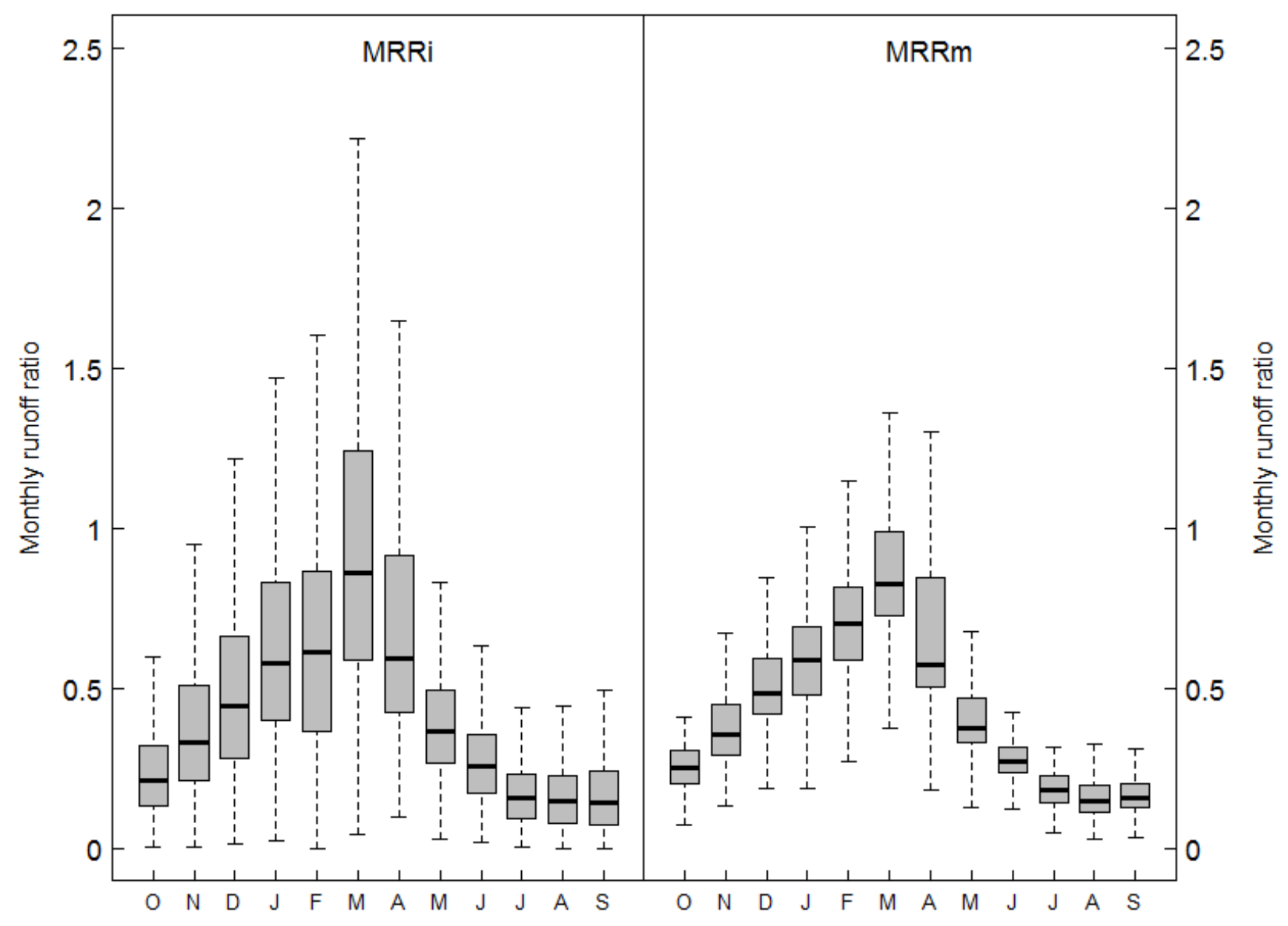

Figure 3.

The different distributions of $M R R_{i}$ and $M R R_{m}$ indicate the degree of interannual variability in hydrologic response among watersheds spanning the Great Lakes basin. While the median values for both temporal characterizations are similar, the interquartile ranges are very different, particularly during winter and spring months. As a result, for management objectives related to the magnitude and timing of high flow events (e.g. potential floods) in ungauged areas, regionalization schemes based on long-term or annual averages may not be suitable. 
The 62 validation watersheds are shown in Figure 4, symbolized according to the deviation of runoff volumes $\left(D_{v}\right)$ for WY 2001-2010. Cumulative runoff was over-predicted in watersheds with a positive $D_{v}$ and under-predicted in watersheds with a negative $D_{v}$. The distributions of $D_{v}$ statistics are shown as boxplots. Runoff was generally over-predicted (median $D_{v} \sim 10 \%$ ) with the $M R R_{m}$ temporal characterization and under-predicted (median $D_{v} \sim-5 \%$ ) with the $M R R_{i}$ temporal characterization.

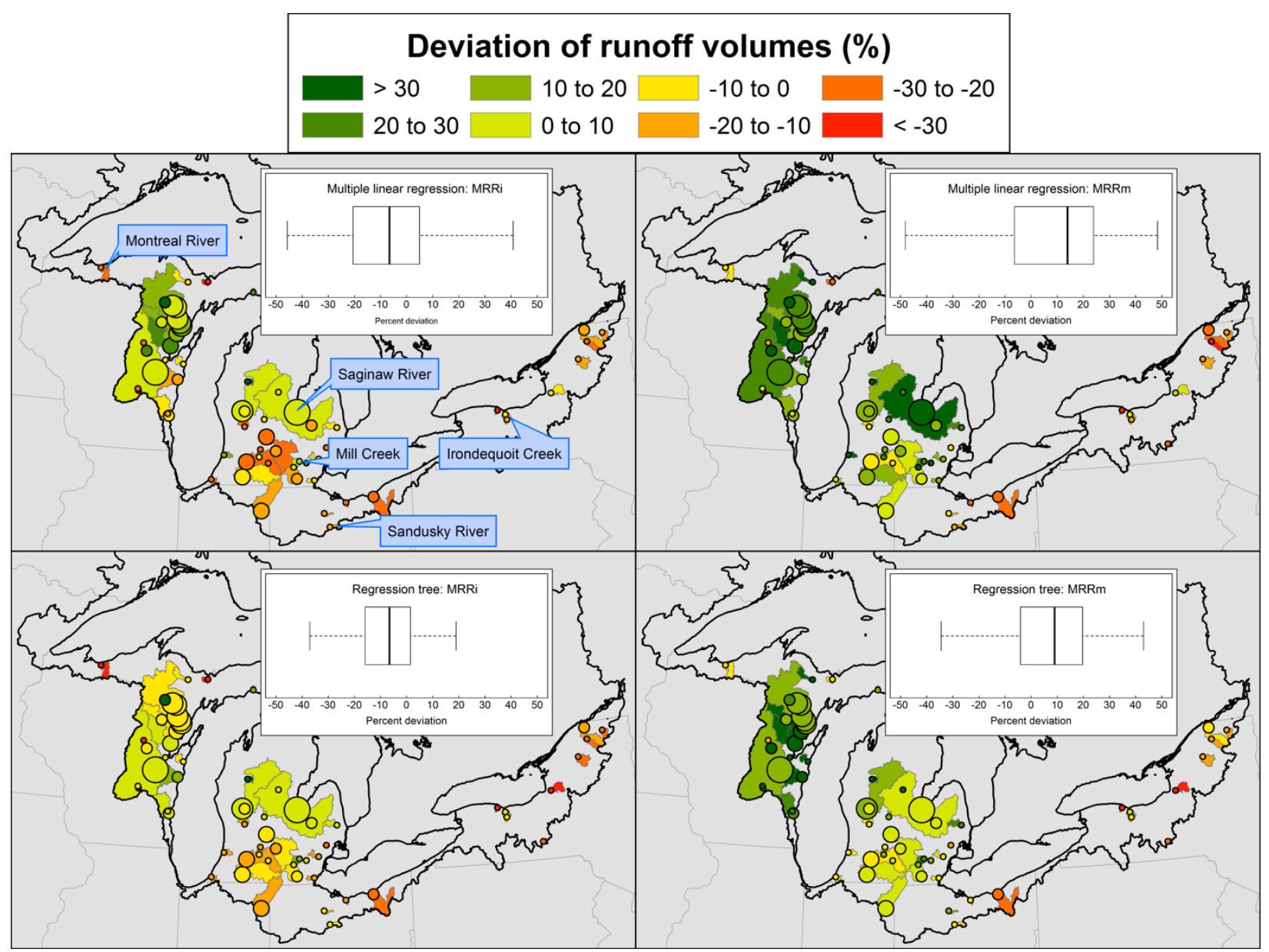

Figure 4.

In some regions, runoff is over- or under-predicted regardless of the model used, such as in western New York and central Michigan. In these cases, there appears to be a relationship 
between watershed drainage area and model bias, where larger watersheds typically overpredict cumulative runoff and smaller watersheds under-predict cumulative runoff. As shown in Table 1, drainage area rarely exhibited a significant linear relationship with runoff ratio. Using the nonlinear, regression tree approach, total drainage area only appeared as a factor in one of the monthly decision trees conditioned on MRR and three of the monthly decision trees conditioned on MRRm. These results, combined with the observations in Figure 4, suggest that neither of the regression approaches used in this study fully incorporated the influence of total drainage area on streamflow discharge.

In other regions, however, the bias depends on the model used, such as in northern Wisconsin and southern Michigan. While the multiple linear regression model included all 12 variables highlighted in Table 1, the regression tree models only included variables deemed important at the scale of the entire Great Lakes basin. Consequently, variables important at more local scales may not have been included in the regression tree models. For example, the percent of precipitation falling as snow and the percent of agricultural land distinguish northern Wisconsin (higher latitude, largely forested) from southern Michigan (lower latitude, largely agricultural). While these watershed physical characteristics have implications for hydrologic response throughout the year, the percent snow variable appeared as a factor in only four of the monthly decision trees conditioned on $\mathrm{MRR}_{\mathrm{i}}$ and three of the monthly decision trees conditioned on $M R R_{m}$, while the percent agricultural land variable appeared as a factor in only six of the monthly decision trees conditioned on MRR $\mathrm{i}_{\mathrm{i}}$ and seven of the monthly decision trees conditioned on $\mathrm{MRR}_{\mathrm{m}}$. These results attest to the challenges of regionalizing hydrologic 
response over large spatial domains containing substantially different watershed physical characteristics at smaller scales of analysis.

The NSE, $R^{2}$ and MAE statistics are given as boxplots in Figure 5. Multiple linear regression using mean runoff ratios performed poorly, while both regression approaches using $\mathrm{MRR}_{\mathrm{i}}$ performed fairly well. The multiple linear regression and regression tree models using the $M R R_{i}$ configuration resulted in median NSE values of 0.52 (range -0.45 to 0.79 ) and 0.54 (range -0.63 to $0-.79)$. These values compare relatively well with models that were evaluated for gauges in as part of the Great Lakes Runoff Intercomparison Project, for which non-assimilative models (i.e. those that did not incorporate discharge observations into simulations) resulted in median NSE values as good as 0.53 for 17 gauges the Lake Michigan basin (Fry et al., 2014). Multiple linear regression using $M R R_{i}$ resulted in the smallest interquartile range for both goodness-of-fit statistics, and was the only model with no NSE values less than zero (that is, higher variance in the model's residuals than in the observed data). The lowest mean absolute errors (in $\mathrm{mm}$ of runoff) were produced using the $M R_{\mathrm{i}}$ temporal characterization of hydrologic response. 


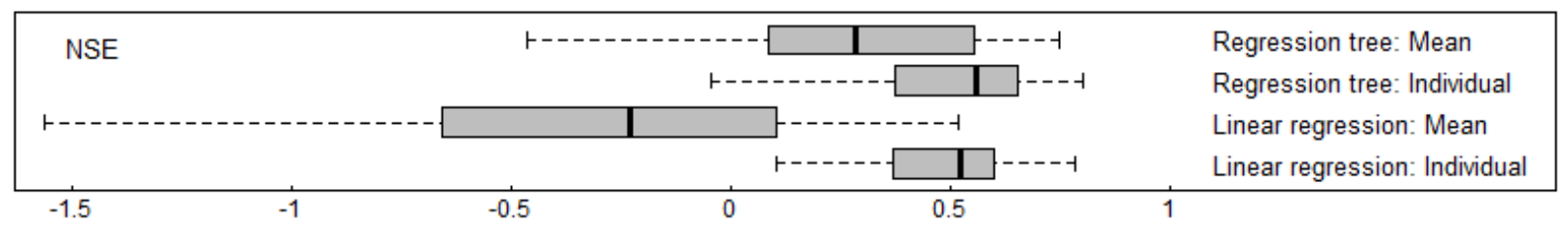

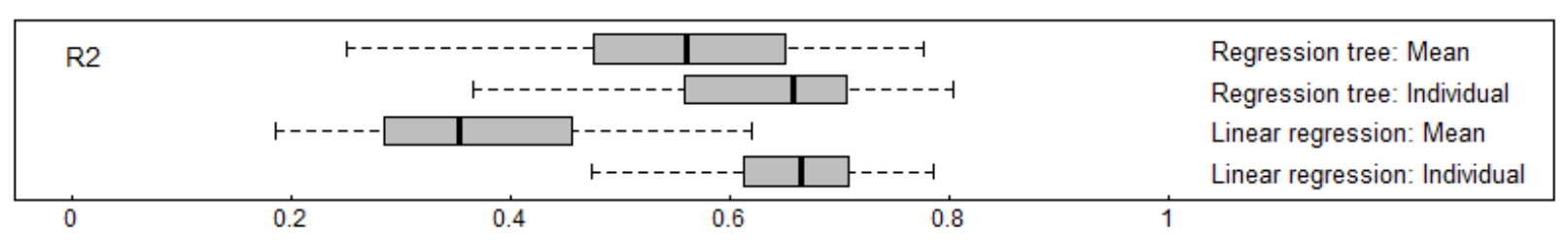

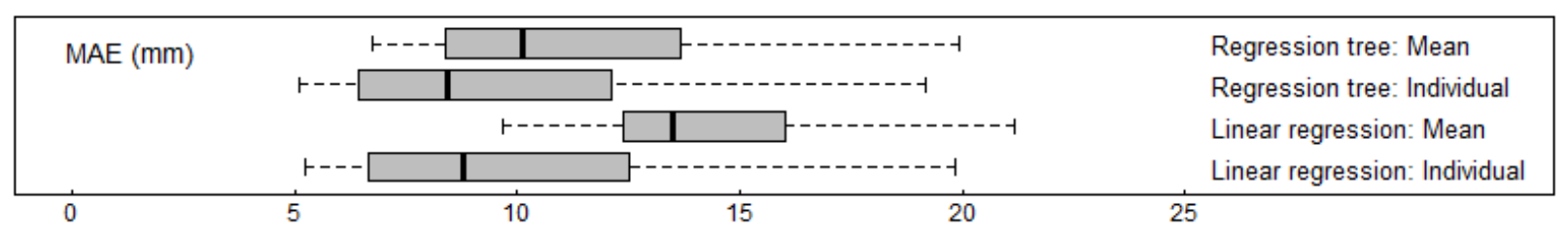

Figure 5.

Based on these metrics, model skill was higher for the MRR models than for the $M R R_{m}$ models, suggesting that the regression models were improved by incorporating the interannual variability of hydrologic response over using long term average hydrologic response.

Additionally, Figure 5 shows that model simulations were far more sensitive to the temporal characterization of runoff ratio than to the type of regression technique used to develop the relationships.

Hydrographs of model-simulated versus observed runoff are shown in Figure 6 for five contrasting validation watersheds spanning the Great Lakes basin. Summary descriptions of these watersheds are given in Table 4 and their locations shown in the upper left panel of Figure 4. In Figure 6, blue lines show observed runoff, while black and red lines show runoff simulated with the $\mathrm{MRR}_{\mathrm{i}}$ and $M \mathrm{MR}_{\mathrm{m}}$ temporal characterizations, respectively. Solid lines display 
simulations from the multiple linear regression approach, while dotted lines display simulations from the regression tree approach.

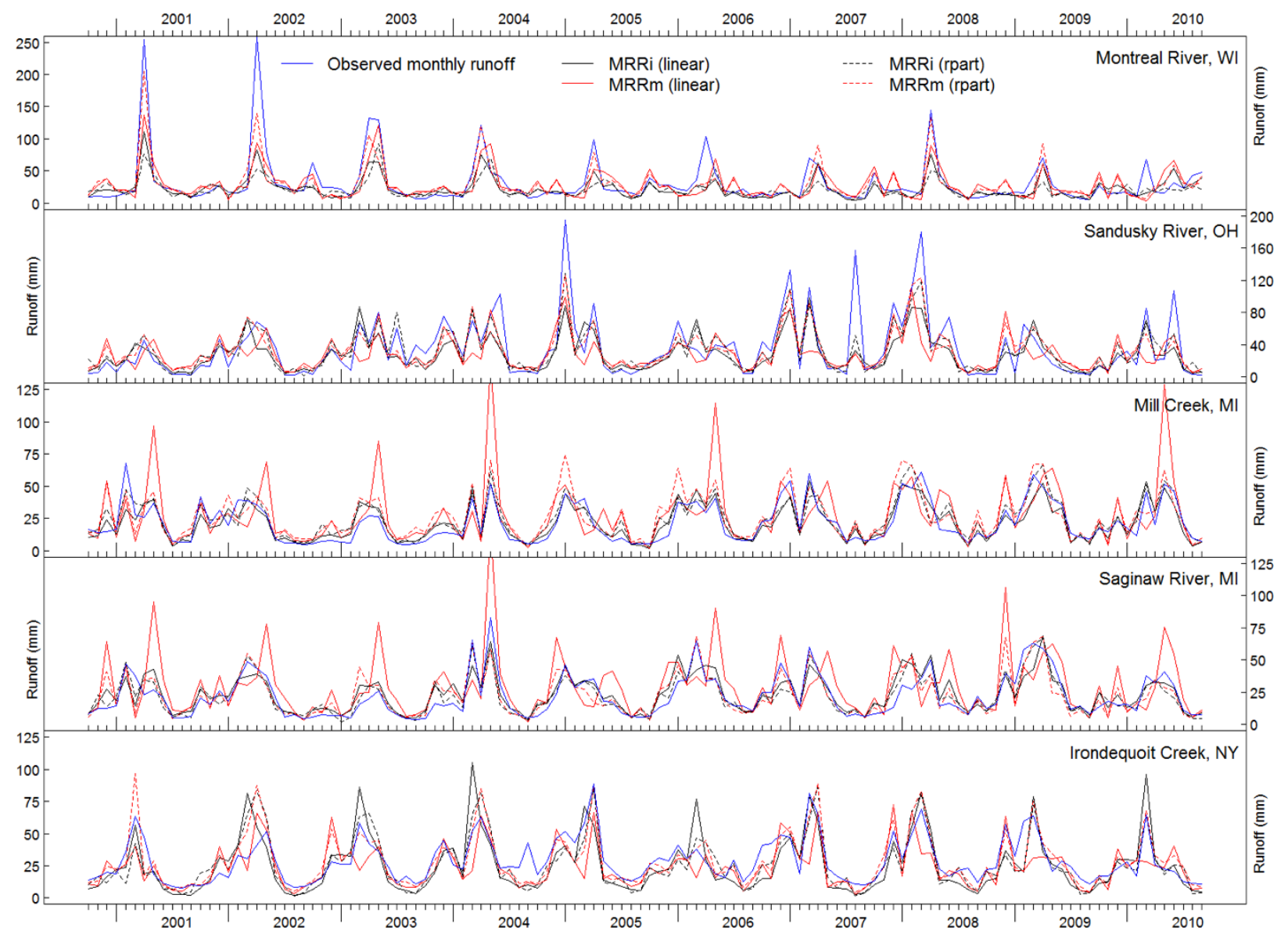

Figure 6.

Comparing the top two hydrographs in Figure 6, the Montreal River exhibits an annual cycle that is consistent from year to year while the Sandusky River hydrograph appears more erratic, with a less apparent annual cycle. Some basic relationships can be inferred between streamflow regimes and watershed physical characteristics, specifically the percent precipitation falling as snow and land cover type. In the Montreal River watershed, the consistent annual cycle (i.e. strong peaks in the spring and low flow in the summer and fall) is 
attributable to (a) colder winters with solid precipitation that does not immediately appear as runoff but instead results in very high flow in the spring months, and (b) lack of impervious surfaces and agricultural areas that would increase high flows and reduce low flows in times with liquid precipitation and reduce the amount of infiltration of melting snow during spring months. On the other hand, hydrograph peaks are observed throughout the year in the Sandusky River watershed. In the Sandusky River watershed, warmer average annual temperatures translate to less snowpack storage potential, and runoff peaks occur following precipitation events during the winter. In summer, hydrograph peaks for the Sandusky River can be attributed to fast runoff from agricultural and developed land cover.

Model bias varies considerably among the five watersheds in Figure 6 . For all models, there is a recurring bias in late winter and early spring with runoff consistently under-predicted for Montreal River and over-predicted for Irondequoit Creek. For Sandusky River, numerous high runoff events in both winter and summer are under-predicted by all models. For Mill Creek and Saginaw River, the models conditioned on mean runoff ratio $\left(M R R_{m}\right)$, particularly the linear model, greatly over-predicted monthly runoff, even in months not experiencing relatively high flows.

To evaluate model skill under different hydrological conditions, we evaluated the coefficient of determination $\left(R^{2}\right)$ at each validation gauge for months that generally have high flows (March, April, and May) and for months with generally low flows (July, August, and September). Interestingly, the two regression models performed differently under different flow regimes. 
Both multiple linear regression models resulted in better $R^{2}$ values during months with low flows than during months with high flows for the majority of validation gauges. The median improvement in $R^{2}$ values for low flow periods over high flow periods was 0.11 (range -0.31 to $0.53)$ and $0.22(-0.53$ to 0.62$)$ for the $M R R_{i}$ and $M R R_{m}$ configurations of the multiple linear regression models, respectively. On the other hand, performance was slightly worse for low flow periods than for high flow periods for the regression tree models. The median improvement in $R^{2}$ values for high flow periods over low flow periods was 0.07 (range -0.29 to $0.56)$ and $0.02(-0.27$ to 0.57$)$ for the $M R R_{i}$ and $M R R_{m}$ configurations of the regression tree models, respectively.

The goodness of fit statistics for spatially aggregated discharge simulations (i.e. the sum of simulated volumetric discharge over the 62 validation gauges compared with the sum of observed volumetric discharge over the 62 gauges) are shown in Table 5. For spatially aggregated simulations, the models conditioned on individual month-year combinations (MRR $)$ result in the best goodness of fit statistics. This relative difference in skill among models was consistent over elapsed time, as shown in Figure 7. Figure 7 also provides an indication of variations in skill over elapsed time. For all models, the goodness of fit metrics stabilize after simulations of about 20 months, with the exception of the linear regression model conditioned to $\mathrm{MRR}_{\mathrm{m}}$, whose skill appears to gradually decrease following an initial improvement. 
— MRRi (linear) - - - MRRi (rpart)

— MRRm (linear) - - - MRRm (rpart)
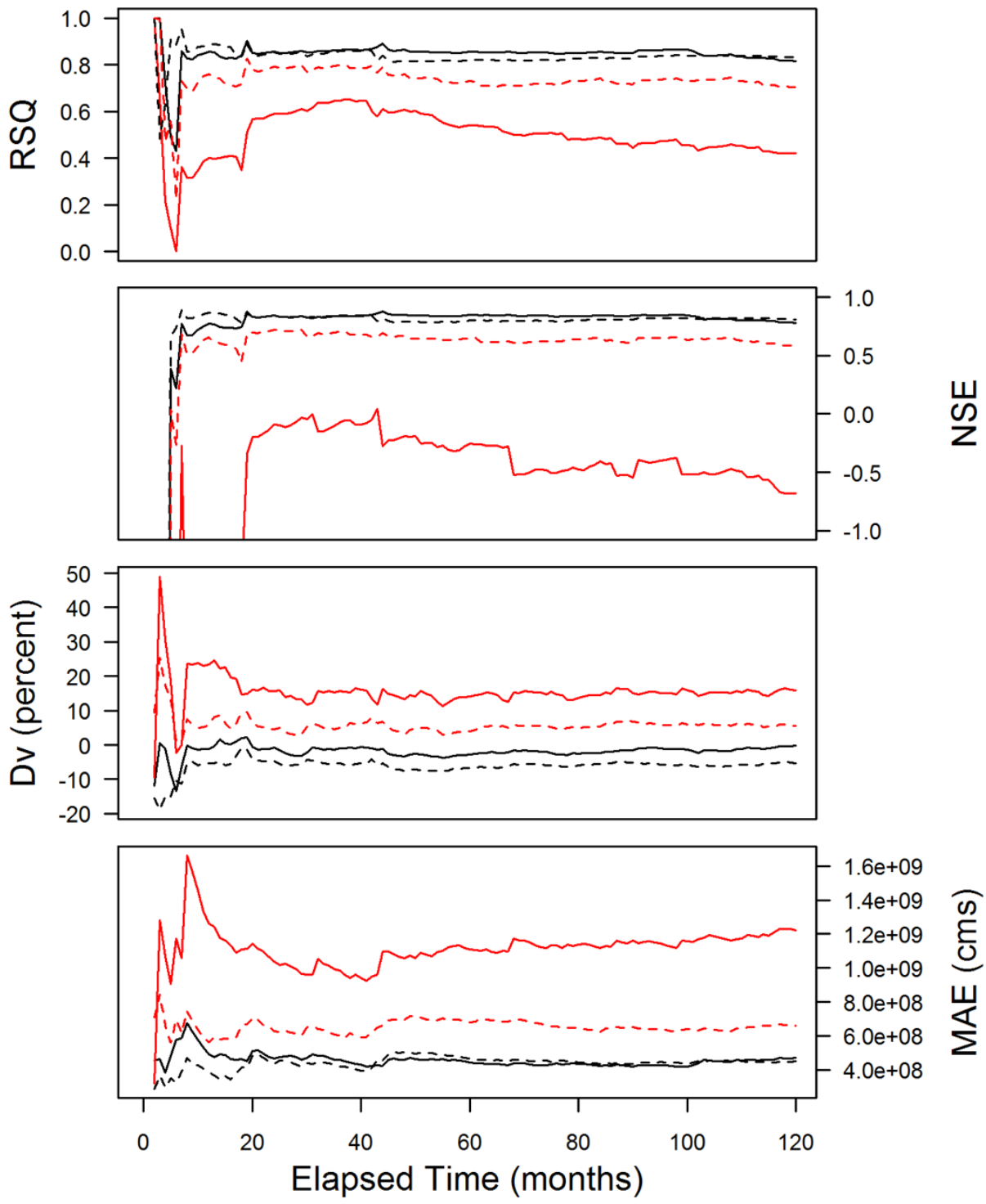

Figure 7.

4. Discussion 
Numerous water resource research and management objectives require knowledge of hydrological processes occurring in ungauged watersheds. Making predictions in ungauged basins through regionalization addresses theoretical and practical means of (1) transferring knowledge of hydrological processes over space from gauged to ungauged watersheds; (2) determining similarities and differences among watersheds, including attempts to establish watershed classification systems; and (3) understanding and accounting for the temporal variability exhibited by hydrologic systems. A great deal of research has been directed towards the first two items. However, regionalization approaches involving hydrologic response indices have rarely accounted for the temporal variability of watershed behavior. This study showed that different temporal characterizations of hydrologic response can result in substantially different model-predicted runoff. Further advances in regionalization research involving hydrologic response indices require the consideration of their temporal as well as spatial variability.

In this research, four regionalization models (multiple linear regression and regression tree, conditioned on both $M R R_{i}$ and $M R R_{m}$ ) were developed to simulate runoff at a monthly time step based on watershed physical characteristics. Results from applications to validation watersheds indicate that model simulations were far more sensitive to the temporal characterization of runoff ratio than to the type of regression technique used to develop the relationships. Specifically, the two regionalization schemes based on $\mathrm{MRR}_{\mathrm{i}}$ performed comparably well alongside contemporary studies using response indices in conjunction with a rainfall-runoff model (e.g. Bulygina et al., 2009; Yadav et al., 2007). Moreover, simulations 
based on the $M R R_{i}$ index were generally acceptable based on the performance ratings of Moriasi et al. (2007).

However, mean monthly runoff ratio $\left(M R R_{m}\right)$ does not appear to provide enough information about watershed behavior to be useful for making predictions in ungauged basins. This conclusion mirrors the opinion expressed by Olden and Poff (2003) that a single index of hydrologic response is insufficient for characterizing the seasonal and interannual variability of hydrologic systems. While $\mathrm{MRR}_{\mathrm{m}}$ accounts for seasonal variations in hydrologic response (the monthly time step), the $\mathrm{MRR}_{\mathrm{i}}$ characterization additionally accounts for interannual variability (the inclusion of all observations over a range of years). This additional level of temporal characterization likely explains the superior performance of $M R R_{i}$ models compared to $M R R_{m}$ models.

Compared to the contrasts exhibited by the temporal characterizations of runoff ratio, there were no substantial differences found between the multiple linear regression and regression tree techniques used to develop the models. In other words, simulations were not sensitive to the watershed classification technique employed to determine hydrologic similarity. These results reflect the contemporary challenges described by Wagener and Montanari (2011) of determining hydrologic similarity among watersheds.

In this research, simulations of runoff in ungauged basins were based solely on empirical relationships between a watershed's physical characteristics and observed hydrologic response. 
This approach is distinct from the more commonly used regionalization approaches that rely on conceptual or process-based rainfall-runoff models to simulate runoff, for example the LBRM and MESH in the Great Lakes basin (see Section 1.2). Whereas rainfall-runoff models attempt to model specific hydrological processes occurring in a watershed, the method presented in this study modeled the watershed as a system, without explicitly modeling constituent routing, storage and loss processes.

An important result of this study is that monthly runoff can be simulated with reasonable skill without recourse to a rainfall-runoff model. This finding is particularly important considering the many regions of the world with sparse stream gauge networks and limited resources for gathering the large amounts of field data required to calibrate a rainfall-runoff model. In such cases, the approach used in this study may be viable for understanding and simulating watershed behavior, particularly over large spatial domains. Additionally, we found that when aggregated over space and time, three of the four model configurations resulted in good goodness of fit statistics after about 20 months of elapsed time, with the exception being the multiple linear regression model conditioned on long term average monthly runoff ratios.

The method used in this study is similar to the area ratio method (ARM; see section 1.2) in its empirical approach for simulating runoff in ungauged watersheds. The primary advantage of the ARM is its utilization of all available streamflow observations at a daily time step. The advantage of the method used in this study is its ability to account for spatial heterogeneity between gauged and ungauged watersheds. Comparisons between these two approaches 
would provide an opportunity to assess the significance of this spatial heterogeneity, while an integration of these two approaches could be developed as an improved alternative to rainfallrunoff models.

Table 2 lists some common hydrology research and management objectives in relation to the perceived appropriateness of temporal scale. The following discussion considers a few of these with examples from the Great Lakes basin.

Monthly forecasts of lake levels are important for transportation, water supply, near-shore habitats, and recreation (Section 1.2). In the Great Lakes basin, forecasts provided by the Advanced Hydrologic Prediction System (Gronewold et al., 2011) require monthly runoff predictions from all ungauged portions of the basin. Although land surface runoff is a key component of the lakes' water budget (and therefore water levels), estimation of the direct impact on lake levels resulting from different methods of estimating runoff is outside the scope of this paper, because net basin supply requires knowledge of overlake precipitation, overlake evapotranspiration, and discharge to/from connecting waterways (Gronewold et al., 2011).

The results of this study contribute important insights for understanding and simulating the land surface runoff component of the regional water budget. Specifically, regionalization schemes based on different temporal characterizations of hydrologic response resulted in substantially different monthly runoff simulations. The $M R R_{i}$ characterization maintains the full variability of observations and provides a realistic range of potential outcomes that may be 
critical for transportation or near-shore habitat functions. On the other hand, management decisions for recreation or municipal water supply may be less sensitive to the prediction of unusually high or low lake levels, and may be better informed by predictions based on long term averages. Management decisions related to contaminant loadings, sediment transport and irrigation availability require consideration of the tradeoffs presented by these modeling alternatives.

Predictions in ungauged basins are also important for generating synthetic runoff time series for use in calibrating rainfall-runoff models. For example, runoff predictions for the entire Great Lakes basin using an area ratio method were used to calibrate the Large Basin Runoff Model (LBRM; Section 1.2) (Croley and Hartmann, 1986). In fact, this approach of conditioning rainfall-runoff models in ungauged basins on regionalized hydrologic response indices is an emerging method for predictions in ungauged basins (Wagener and Montanari, 2011). As an alternative to the simple area ratio method, the models developed in this study could be used to generate historical monthly runoff for re-calibration of LBRM or other rainfall-runoff models. Further work is required to determine which temporal characterization of hydrologic response provides a more robust basis for rainfall-runoff model calibration.

Hydrologic response indices are commonly used to generate ancillary information that can be applied to watershed classification schemes (e.g. Sawicz et al., 2001) or to constrain prior parameter spaces of rainfall-runoff models (e.g. Bulygina et al., 2009; Yadav et al., 2007). This study indicates this ancillary information will be substantially different for different temporal 
characterizations of runoff ratio. The studies reviewed here have focused on long-term characterizations of hydrologic response. These studies have provided important insights for PUB research, and additional insights may be expected from the inclusion of multiple temporal characterizations of any response index.

In light of the previous discussion and this study's results, the multiple linear regression and regression tree models conditioned on $\mathrm{MRR}_{\mathrm{i}}$ observations appear promising for application to the entire Great Lakes basin. Important next steps for this research include applying these models to the entire Lake Michigan basin (which is entirely within the U.S.) followed by application to the entire Great Lakes basin as data for the Canadian portion of the basin become available. This agenda provides the opportunity for inter-comparisons, including crossvalidation at gauged locations, with (1) the area ratio method, to assess model sensitivity to spatial heterogeneity of watershed physical characteristics and (2) process-based rainfall-runoff models such as LBRM and MESH, to assess the viability of predicting runoff in ungauged basins directly from regionalized hydrologic response indices.

\section{Conclusion}

Hydrologic response indices have frequently been employed in contemporary research related to predictions in ungauged basins. In this study, we developed regression models relating a hydrologic response index (monthly runoff ratio) to a twelve watershed physical characteristics for 163 watersheds in the Great Lakes basin. For the dependent variable in these regression 
models, we used monthly runoff ratio as the indicator of hydrologic response and defined it at two temporal scales: (1) treating all monthly runoff ratios as individual observations and (2) using the mean of these monthly runoff ratios for each watershed as a representative observation. Results from this study contribute important insights for contemporary research involving hydrologic predictions in ungauged watersheds.

Application of our models to 62 validation watersheds throughout the Great Lakes basin indicated that monthly runoff can be simulated with reasonable skill using empirical relationships between runoff ratio and watershed physical characteristics. These results suggest the viability of empirical approaches to simulating runoff in ungauged basins. This finding is significant given the many regions of the world with sparse gaging networks and limited resources for gathering the field data required to calibrate rainfall-runoff models. Results from this study also indicated that model simulations were far more sensitive to the temporal characterization of hydrologic response than to the type of regression technique employed. This result is particularly important given the numerous applications of hydrologic response indices in contemporary research for making predictions in ungauged watersheds. These predictions are essential for water resource management in the Great Lakes basin and worldwide.

Acknowledgements 
This research was funded by a fellowship from the Cooperative Institute for Limnology and Ecosystems Research, with additional support from the University of Wisconsin-Milwaukee Geography Department. Special thanks to Tim Hunter at NOAA-GLERL for processing the meteorology and streamflow data used in this study.

\section{References}

Abdulla, F.A., Lettenmaier, D.P., 1997. Application of regional parameter estimation schemes to simulate the water balance of a large continental river. J. Hydrol. 197(1-4), 258-285.

Ali, G.A., Roy, A.G., Turmel, M.C., Courchesne, F., 2010. Multivariate analysis as a tool to infer hydrologic response types and controlling variables in a humid temperate catchment. Hydrol. Process., 24(20), 2912-2923.

Bárdossy, A., 2007. Calibration of hydrological model parameters for ungauged catchments. Hydrol. Earth Syst. Sci. 11(2), 703-710.

Bao, Z., Zhang, J., Liu, J., Fu, G., Wang, G., He, R., Yan, X., Jin, J., Liu, H., 2012. Comparison of regionalization approaches based on regression and similarity for predictions in ungaged catchments under multiple hydro-climatic conditions. J. Hydrol. 466-467, 37-46.

Berger, K.P., Entekhabi, D., 2001. Basin hydrologic response relations to distributed physiographic descriptors and climate. J. Hydrol. 247(3-4), 169-182.

Beven, K.J., 2000. Uniqueness of place and process representations in hydrological modelling. Hydrol. Earth Syst. Sci. 4(2), 203-213.

Beven, K., 2006. A manifesto for the equifinality thesis. J. Hydrol. 320(1-2), 18-36. 
Breiman, L., Friedman, J., Stone, C. J., Olshen, R.A., 1984. Classification and regression trees. Boca Raton, FL: Chapman \& Hall/CRC.

Bulygina, N., McIntyre, N., Wheater, H., 2009. Conditioning rainfall-runoff model parameters for ungaged catchments and land management impacts analysis. Hydrol. Earth Syst. Sci. 13(6), 893-904.

Changnon, S., 1987. Climate fluctuations and record-high levels of Lake Michigan. Bull. Am. Meteor. Soc. 68(11), 1394-1402.

Choi, W., Keuser, A., Becker, S., 2012. Identification of mid-latitudinal regional and urban temperature variabilities based on regional reanalysis data. Theor. Appl. Clim. 107(1-2), 87-98.

Coon, W.F., Murphy, E.A., Soong, D.T., Sharpe, J.B., 2011. Compilation of watershed models for tributaries to the Great Lakes, United States, as of 2010, and identification of watersheds for future modeling for the Great Lakes Restoration Initiative: U.S. Geological Survey Open-File Report 2011-1202, 23 p. (Also available at http://pubs.usgs.gov/of/2011/1202).

Croley, T.E., Hartmann, H.C., 1986. NOAA Technical Memorandum ERL GLERL-61: Near-RealTime Forecasting of Large-Lake Water Supplies; A User's Manual. Ann Arbor, MI.

Fry, L.M., Gronewold, A.D., Fortin, V., Buan, S., Clites, A., Luukkonen, C., Restrepo, P., 2014. The Great Lakes Runoff Intercomparison Project Phase 1: Lake Michigan (GRIP-M). J. Hydrol., submitted. 
Fry, L.M., Hunter, T.S., Phanikumar, M.S., Fortin, V., Gronewold, A.D., 2013. Identifying streamgage networks for maximizing the effectiveness of regional water balance modeling. Water Resour. Res., 49(5), 2689-2700.

Gronewold, A.D., Clites, A.H., Hunter, T.S., Stow, C.A., 2011. An appraisal of the Great Lakes Advanced Hydrologic Prediction System. J. Great Lakes Res. 37(3), 577-583.

Gronewold, A. D., \& Fortin, V. (2012). Advancing Great Lakes Hydrological Science Through Targeted Binational Collaborative Research. Bulletin of the American Meteorological Society, 93(12), 1921-1925.

Gronewold, A.D., Stow, C.A., 2014. Water loss from the Great Lakes. Science, 343(6175), 10841085.

He, C., 1997. Modeling hydrologic impact of withdrawing the Great Lakes water for agricultural irrigation. J. Amer. Water Resour. Assoc. 33(5), 1055-1068.

He, C., DeMarchi, C., 2010. Modeling spatial distributions of point and nonpoint source pollution loadings in the Great Lakes watersheds. Int. J. Environ. Sci. Eng. 2(1), 24-30. Hrachowitz, M., Savenije, H.H.G., Blöschl, G., McDonnell, J.J., Sivapalan, M., Pomeroy, J.W., Cudennec, C., 2013. A decade of Predictions in Ungauged Basins (PUB)-a review. Hydrol. Sci. Journal, 58(6), 1198-1255.

Hunter, T.S., Croley II, T.E., 1993. Great Lakes Monthly Hydrological Data, NOAA Data Report ERL GLERL. Springfield, VA. Retrieved from http://www.glerl.noaa.gov/data/arc/hydro/mnth-hydro.html 
Kay, A.L., Jones, D.A., Crooks, S.M., Calver, A., Reynard, N.S., 2006. A comparison of three approaches to spatial generalization of rainfall-runoff models. Hydrol. Process. 20(18), 3953-3973.

Kokkonen, T.S., Jakeman, A.J., Young, P.C., Koivusalo, H.J., 2003. Predicting daily flows in ungauged catchments: Model regionalization from catchment descriptors at the Coweeta Hydrologic Laboratory, North Carolina. Hydrol. Process. 17(11), 2219-2238.

Laaha, G., Blöschl, G., 2006. A comparison of low flow regionalisation methods-catchment grouping. J. Hydrol., 323(1-4), 193-214.

Lee, D.H., Clites, A.H., Keillor, J.P., 1997. Assessing risk in operational decisions using Great Lakes probabilistic water level forecasts. Environ. Manag. 21(1), 43-58.

McIntyre, N., Lee, H., Wheater, H., Young, A., Wagener, T., 2005. Ensemble predictions of runoff in ungaged catchments. Water Resour. Res. 1(12), W12434.

Merz, R., Blöschl, G., 2004. Regionalisation of catchment model parameters. J. Hydrol. 287(1-4).

Moriasi, D. N., Arnold, J. G., Van Liew, M. W., Bingner, R. L., Harmel, R. D., Veith, T. L. (2007). Model evaluation guidelines for systematic quantification of accuracy in watershed simulations. Transactions of the American Society of Agricultural and Biological Engineers, 50(3), 885-900.

Nash, J. E., \& Sutcliffe, J. V. (1970). River flow forecasting through conceptual models part I - A discussion of principles. Journal of Hydrology, 10(3), 282-290.

Nijssen, B., O'Donnell, G.M., Lettenmaier, D.P., Lohmann, D., Wood, E.F., 2001. Predicting the discharge of global rivers. J. Clim. 14(15), 3307-3323. 
Norton, D.C., Bolsenga, S.J., 1993. Spatiotemporal trends in lake effect and continental snowfall in the Laurentian Great Lakes, 1951-1980. J. Clim. 6(10), 1943-1956.

Olden, J.D., Poff, N.L., 2003. Redundancy and the choice of hydrologic indices for characterizing streamflow regimes. River Res. Appl. 19(2), 101-121.

Oudin, L., Andreassian, V., Perrin, C., Michel, C., Le Moine, N., 2008. Spatial proximity, physical similarity, regression and ungaged catchments: A comparison of regionalization approaches based on 913 French catchments. Water Resour. Res. 44(3), W03413.

Parajka, J., Merz, R., Blöschl, G., 2005. A comparison of regionalisation methods for catchment model parameters. Hydrol. Earth Syst. Sci. 9(3), 157-171.

Pietroniro, A., Fortin, V., Kouwen, N., Neal, C., Turcotte, R., Davison, B., Verseghy, D., Soulis, E.D., Caldwell, R., Evora, N., Pellerin, P., 2007. Development of the MESH modelling system for hydrological ensemble forecasting of the Laurentian Great Lakes at the regional scale. Hydrol. Earth Syst. Sci. 11(4), 1279-1294.

Post, D.A., 2009. Regionalizing rainfall-runoff model parameters to predict the daily streamflow of ungauged catchments in the dry tropics. Hydrol. Res. 40(5), 433-444.

Post, D.A., Jakeman, A.J., 1999. Predicting the daily streamflow of ungauged catchments in SE Australia by regionalising the parameters of a lumped conceptual rainfall-runoff model. Ecol. Model. 123(2-3), 91-104.

Reichl, J.P.C., Western, A.W., Mclntyre, N.R., Chiew, F.H.S., 2009. Optimization of a similarity measure for estimating ungaged streamflow. Water Resour. Res. 45, W10423.

Robertson, D.M., Saad, D.A., 2003. Environmental water-quality zones for streams: A regional classification scheme. Environ. Manag. 31(5), 581-602. 
Samuel, J., Coulibaly, P., Metcalfe, R.A., 2011. Estimation of continuous streamflow in Ontario ungauged basins: Comparison of regionalization methods. J. Hydrol. Eng. 16(5).

Sawicz, K., Wagener, T., Sivapalan, M., Troch, P.A., Carrillo, G., 2011. Catchment classification: Empirical analysis of hydrologic similarity based on catchment function in the eastern USA. Hydrol. Earth Syst. Sci. 15(9), 2895-2911.

Sefton, C.E.M., Howarth, S.M., 1998. Relationships between dynamic response characteristics and physical descriptors of catchments in England and Wales. J. Hydrol. 211(1-4), 1-16.

Seibert, J., 1999. Regionalisation of parameters for a conceptual rainfall-runoff model. Agric. For. Meteor. 98-9, 279-293.

Shamir, E., Imam, B., Morin, E., Gupta, H.V., Sorooshian, S., 2005. The role of hydrograph indices in parameter estimation of rainfall-runoff models. Hydrol. Process. 19(11), 21872207.

Sivapalan, M., Takeuchi, K., Franks, S., Gupta, V., Karambiri, H., Lakshmi, V., Liang, X., McDonnell, J.J., Mendiondo, E.M., O’Connell, P.E., Oki, T., Pomeroy, J.W., Schertzer, D., Uhlenbrook, S., Zehe, E., 2003. IAHS decade on predictions in ungaged basins (PUB), 2003-2012: Shaping an exciting future for the hydrological sciences. Hydrol. Sci. J. 48(6), 857-880.

R Development Core Team., 2011. R: A language and environment for statistical computing. Vienna, Austria: R Foundation for Statistical Computing. Retrieved from http://www.rproject.org/

Snelder, T.H., Lamouroux, N., Leathwick, J.R., Pella, H., Sauquet, E., Shankar, U., 2009. Predictive mapping of the natural flow regimes of France. J. Hydrol., 373(1-2), 57-67. 
Therneau, T.M., Atkinson, E.J., 1997. An Introduction to Recursive Partitioning using the RPART Routines. Technical Report 61, Section of Biostatistics, Mayo Clinic, Rochester. http://www.mayo.edu/hsr/techrpt/61.pdf.

USGS, 2011. GAGES-II: Geospatial Attributes of Gages for Evaluating Streamflow. http://water.usgs.gov/lookup/getspatial?gagesII_Sept2011.

USGS, 2012. Coordinated effort between the United States Department of Agriculture-Natural Resources Conservation Service (USDA-NRCS), the United States Geological Survey (USGS), and the Environmental Protection Agency (EPA). The Watershed Boundary Dataset (WBD) was created from a variety of sources from each state and aggregated into a standard national layer for use in strategic planning and accountability. Watershed Boundary Dataset for all Great Lakes states. Available URL: http://datagateway.nrcs.usda.gov [Accessed 01/09/2012].

Valipour, M., Banihabib, M.E., Behbahani, S.M.R.., 2013. Comparison of the ARMA, ARIMA, and the autoregressive artificial neural network models in forecasting the monthly inflow of Dez dam reservoir. J.Hydrol. 476, 433-441.

Vicente-Serrano, S.M., Begueria, S., Lopez-Moreno, J.I., 2010. A multiscalar drought index sensitive to global warming: The standardized precipitation evapotranspiration index. J. Clim. 23(7), 1696-1718.

Vogel, R.M., 2006. Regional calibration of watershed models. In V.P. Singh and D.F. Frevert (Eds.), Watershed Models (pp. 549-567). Boca Raton, FL: CRC Press. 
Wagener, T., Wheater, H., 2006. Parameter estimation and regionalization for continuous rainfall-runoff models including uncertainty. J. Hydrol. 320(1-2), 132-154.

Wagener, T., Montanari, A., 2011. Convergence of approaches toward reducing uncertainty in predictions in ungaged basins. Water Resour. Res. 47, W06301.

Wagener, T., Wheater, H.S., Gupta, H.V., 2004. Rainfall-runoff modeling in gaged and ungaged catchments. London: Imperial College Press.

Wolter, P.T., Johnston, C.A., Niemi, G.J., 2006. Land use land cover change in the US Great Lakes basin 1992 to 2001. J. Great Lakes Res. 32(3), 607-628.

Yadav, M., Wagener, T., Gupta, H., 2007. Regionalization of constraints on expected watershed response behavior for improved predictions in ungaged basins. Adv. Water Resour. 30(8), 1756-1774. 